\title{
INFORMATION SYSTEMS PRACTICE FOR DEVELOPMENT IN AFRICA: Results from INDEHELA
}

\author{
Mikko Korpela \\ Anja Mursu \\ University of Kuopio \\ Kuopio, Finland \\ H. Abimbola Soriyan \\ Obafemi Awolowo University \\ Ile-Ife, Nigeria \\ Retha de la Harpe \\ Cape Peninsula University of Technology \\ Cape Town, South Africa \\ Esselina Macome \\ Eduardo Mondlane University \\ Maputo City, Mozambique
}

\begin{abstract}
In this paperwe search for answers to the question: Can information systems development (ISD) in Africa by African IS practitioners contribute to human development in Africa? More specifically, we ask if everyday ISD practice in Nigeria can contribute to people's health in Nigeria. We summarize the results of European-African research collaboration spanning more than 15 years. A spectrum of research methods was used from 1998 through 2001 , including a survey on software industry $(N=103)$, a survey on IS education in universities $(N=26)$, five case studies in industry, and reflection on action in a university-based project. An industry profile of software companies and their ISD practice is presented and contrasted with the education available. Implications are drawn for ISD practitioners and methodological lessons identified for IS research in general. In the discussion, the view is expanded from Nigeria to other African and developing countries.
\end{abstract}

Keywords Systems development, Africa, Nigeria, research methods, activity theory, healthcare, context, sustainability

Please use the following format when citing this chapter:

Korpela, M., Mursu, A., Soriyan, H.A., de la Harpe, R., and Macome, E., 2006, in IFIP International Federation for Information Processing, Volume 208, Social Inclusion: Societal and Organizational Implications for Information Systems, eds. Trauth, E., Howcroft, D., Butler, T., Fitzgerald, B., DeGross, J., (Boston: Springer), pp. 15-35. 


\section{INTRODUCTION: ENDOGENOUS SYSTEMS DEVELOPMENT AND HEALTHCARE IN NIGERIA}

The ultimate challenge of this conference can be squeezed into the question: How can we make a better world with ICTs? In defining the better world, we rely on Sen, the only Nobel prize winner in development economics, who argues that "development can be seen as a process of expanding the real freedoms that people enjoy" $(1999$, p. 20). If ICTs are to have a significant role in human development, in Sen's terms not just economic development - the real test is to see if ICTs can have a role in the least economically and technologically "developed" region in the world today, Sub-Saharan Africa (UNDP 2001). It is in parts of the world like Africa that stand to gain the most from the promise of ICTs, but Sub-Saharan Africa faces the greatest challenges in achieving the gains and is the least studied region in Information Systems (Mbarika et al. 2005). The potential for ICTs to affect human development is most strikingly seen in Africa, but deeper understanding gained there can enlighten socially concerned information systems researchers and practitioners in North America and Europe as well.

The relation between a better world and an appropriate technology was defined more than a quarter-century ago as follows:

Technology should be considered "appropriate" when its introduction into a community creates a self-reinforcing process internal to the same community, which supports the growth of the local activities and the development of indigenous capabilities as decided by the community itself(Pellegrini 1980, p. $1)$.

Studies on the relation between ICTs and development in Africa mainly focus on national economic development and transfer of technology (e.g., Mbarika et al. 2005, Musa et al. 2005). While our interest is on human development, the main emphasis should be on endogenous processes by people in Africa in appropriating ICTs to support the expansion of their real freedoms. Exogenous processes of technology transfer by external actors can and do have a role, but they should also be assessed from the viewpoint of how well they support the processes internal to Africa and developing countries in general.

The definition above of appropriate technology does not refer to any static characteristics of a technology, but to the process of its introduction to a community. In discussing ICTs, the introduction of computer-based technologies into organizations and other social settings is understood in Information Systems as information systems development (ISD); that is, the development of organizational systems comprising people, computer-based and other technologies, and processes (Avison 1997; Walsham 1993). It is thus important to study the endogenous processes of ISD in developing countries and Africa in particular.

In this paper we summarize the results of over 15 years of European-African research collaboration focusing on the practice of ISD in Sub-Saharan Africa. While the bulk of the research was conducted in Nigeria, the discussion is based on experience from Africa in general and Mozambique and South Africa in particular. Nigeria is by far the most populous country in Africa, with about 120 million people and a gross 
domestic product of US\$ 860 per capita in 2002 , ranking the $151^{\text {st }}$ of 177 countries in the Human Development Index (UNDP 2004). In terms of the human development index, Nigeria is an average Sub-Saharan African country, but it has huge human and natural resources.

In the Nigerian context, endogenous processes of information systems development emerged initially from the 1960 s as in-house development in government ministries, universities, the oil industry, and banks, but by 1988 there were 200 companies offering computer-related services (Korpela 1994; Nwachuku 1989). To study endogenous information systems development, we focused on companies in Nigeria that have software-related activities. While health is one of the most fundamental elements of the basic freedom to survive (Sen 1999), we had a special focus on how information systems practice is related to improving health care (Berg et al. 2003). Our research thus initially aimed at searching for answers to the question: Can ISD in Nigeria by Nigerians contribute to human development, specifically to people's health, in Nigeria?

In the rest of the paper we first elaborate on the origins, objectives, units of analysis, and design of the research conducted in Nigeria, followed by the spectrum of methods applied. The next sections summarize the status of ISD in Nigeria and the implications that can be drawn for ISD practitioners. In the discussion section, we identify methodological lessons for IS research in general and expand the view from Nigeria to other African and developing countries. Finally, we conclude by summarizing the contributions.

\section{OBJECTIVES OF THE INDEHELA RESEARCH PROGRAM}

\subsection{The Origins and Actors}

The research presented in this paper had its origins in 1989, when a doctoral student from the University of Kuopio in Finland stayed as a visiting researcher at the Obafemi Awolowo University in Nigeria. A very rudimentary hospital information system, running on a stand-alone $\mathrm{PC}$, was then jointly developed (Daini et al. 1992). This gave rise to regular research collaboration between the two universities. The group was then authorized to organize the first Health Informatics in Africa (HELINA) conference in 1993 (Mandil et al. 1993). Several participants felt that ICT could be used more broadly to facilitate healthcare in Africa if appropriate software applications were developed specifically for that purpose.

In the following 3 years, a group of activists from Finland and Norway in Europe and Nigeria, South Africa, Ghana, Senegal, and Zimbabwe in Africa tried to raise funding for a large research and development initiative under the name Informatics Development for Health in Africa (INDEHELA 1995/2006). When this proved to be too difficult, the Norwegian and South African partners embarked on district-level information management (Braa et al. 2004), while the Finnish and Nigerian partners continued work on the hospital information system. In 1998, the latter partners received Finnish funding for academic research on Methods for Informatics Development for Health in Africa (INDEHELA-Methods). This paper reflects on what was achieved. 


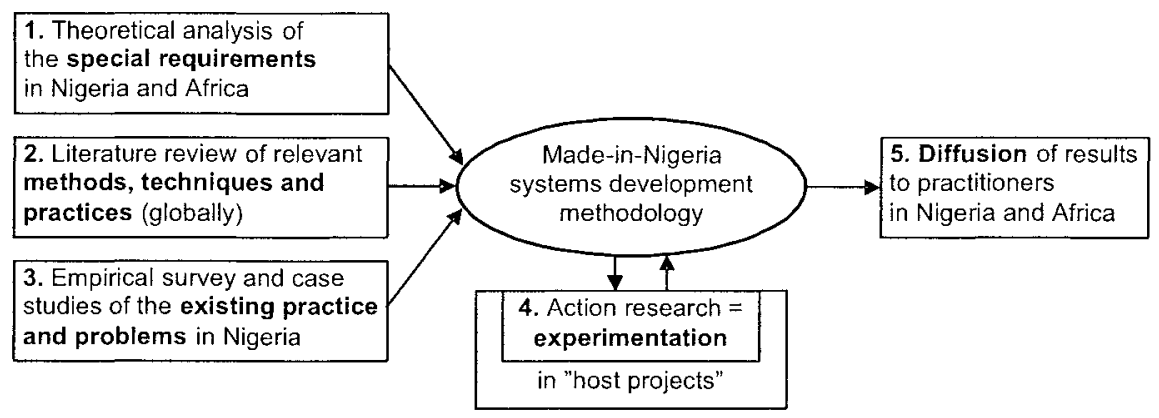

Figure 1. The overall research design in 1998-2001 (from 1997 research proposal, INDEHELA 1995/2006).

\subsection{Research Objectives, Units, and Design: 1998-2001}

The objective of INDEHELA-Methods in Nigeria was to produce an information systems development methodology appropriate for the special requirements of the SubSaharan African context, particularly in the health sector. The required outcome was later characterized as ISD methodologies for severely constrained conditions. In order to produce that outcome, the research design, depicted in Figure 1 was specified (INDEHELA 1995/2006).

Three inputs were identified. First, the general requirements for the methodology had to be specified through theoretical analysis of the specific conditions. Second, the relevant raw materials of methods, techniques, and practices developed for other conditions needed to be identified through literature review. Third, more empirical information was needed on how ISD was currently practiced in Nigeria, so that the outcome would be based on actually perceived needs.

The fourth part of the design was to experiment with ideas gathered from the three inputs in practice, to gradually construct an improved methodology (which was seen as a collection of guidelines, practices, and methods rather than a strict formalism). Action research in a pilot case setting was suggested for that purpose. The final part, after the research project, was to find out how the methodology could be diffused back to everyday use.

The literature surveys in part 1 of the design drew mainly from the conferences of IFIP Working Group 9.4, Social Implications of Computers in Developing Countries, and from the two journals that focus on IS in developing countries. Part 2 drew mainly from IFIP WG8.2, Information Systems and Organizations, from participatory design and activity theory conferences, and related journals. This laid the foundation for the empirical parts 3 and 4, which are described in more detail below.

Research in IS can focus on units of analysis on four integrative levels of increasingly widening scopes: individual, group, organization and society (Korpela et al. 2001; Walsham 2000). INDEHELA-Methods operated on all but the individual level. 

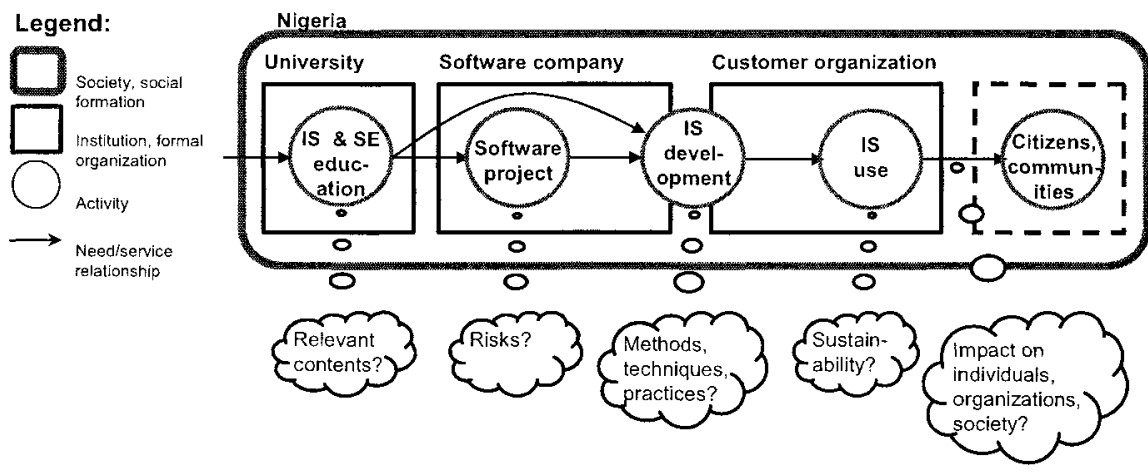

Figure 2. The Core Research Framework: Research Context, Objects, and Questions

Figure 2 depicts the units of analysis as generic concepts (legend) and in specific terms (Korpela et al. 2000). The main emphasis was on the group level. Activity theory (Engeström 1987; Korpela et al. 2004) emerged as the analytical tool on that level, since it provided a practicable theory on the structure of a group activity like ISD (Korpela 1994; see Figure 4). The core chain of activities around ISD from university education and software development to the use of ICT in everyday practice was included.

It was intuitively considered important to study the activities within their organizational contexts of universities, software companies, and customer organizations (rectangular boxes in Figure 2). Finally, Nigeria as a country was included as the broadest unit of analysis.

\subsection{Research Questions: 1998-2001}

Very broad research questions were identified, since no prior research existed on ISD practice in Africa (Figure 2). A Nigerian and a Finnish Ph.D. student embarked on a number of basic (RQ1-3) and specific (RQ4-6) research questions (Soriyan 2004; Mursu 2002).

RQ1: What kinds of software companies are there in Nigeria? What is the size of the software industry? What human resources, skills, infrastructure, and so on, do they have?

RQ2: What kinds of customers do the software companies have? How does IS benefit them?

RQ3: How many universities provide IS education? What kind of IS education do they provide, and what are their resources?

RQ4: What are the methods, techniques, and practices used in ISD by the software companies and the customer organizations? How can risks in software projects be identified, monitored, and mitigated? 
RQ5: Is there any impact of the information systems on the services rendered by the customer organizations to their clients? How can the sustainability of an information system be facilitated by improved ISD methods?

RQ6: Is the IS education provided by the universities relevant to the software and IS development activities of the software companies?

\section{METHODS FOR LANDSCAPE AND IN-DEPTH VIEWS}

The descriptive empirical research questions and the constructive practical objectives clearly did not imply a hypothesis-testing, positivist approach, but an interpretive and critical stand on the phenomena under study (Orlikowski and Baroudi 1991). A combination of methods was selected for getting both a "landscape view" and an "indepth view," as depicted in Figure 3 (modified from Mursu [2002] and Soriyan [2004]).

\subsection{Getting an Insight: Reflecting on Action in Real-Life ISD}

The initial purpose was to involve practitioners from one or two software companies in analyzing their current ISD practices and then proceed to experimenting with modified practices, developed by collaborative action by the practitioners and the researchers in the mood of developmental work research (Engeström 1987). It was soon realized, however, that action research in the true sense of the concept (Checkland 1991) was not feasible in companies until after much foundation-laying.

Action research is the research method through which researchers can get the most tangible insight into ISD. Since none of the researchers had initially any significant experience in ISD in Nigeria, the joint hospital information system activities of the two universities and the local teaching hospital in Nigeria was taken as the second-best option for experimenting with ISD methods in practice (lower center of Figure 3).

The initial system from 1989 was modernized and expanded by the Department of Computer Science and Engineering in the late 1990s, named MINPHIS (Made In Nigeria Primary-care and Hospital Information System) and later installed in a few new hospitals. However, the research and the practical development did not proceed at the same pace, so there was not much experimentation in or feedback from MINPHIS during INDEHELA-Methods. Reflecting on the researchers' experience in MINPHIS was still important to their insight.

\subsection{In-Depth View from Case Studies Analyzed through Activity Theory}

The main method for acquiring an in-depth view of ISD in Nigeria was exploratory case studies (Myers 1997/2005; Yin 1994). Semi-structured, open-ended interviews were conducted in five software companies (lower right-hand side of Figure 3 ), focusing 


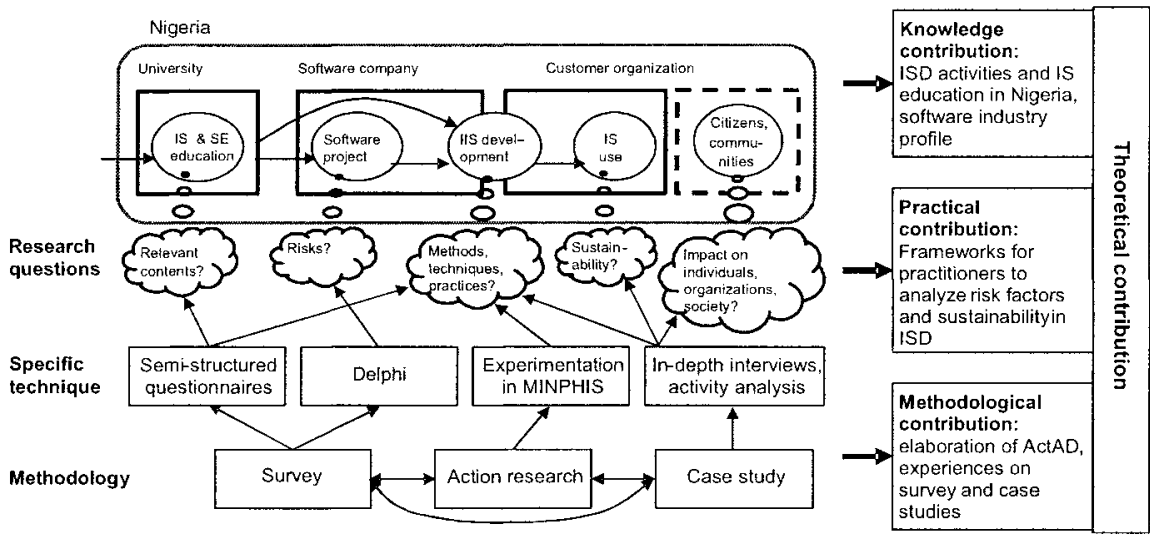

Figure 3. Research Methods and Intended Contributions in 1998-2001

on one current or recently ended ISD project in each case. Three of the companies were selected as good representatives of different types of companies--local and foreign ownership, big and small, package and tailoring oriented (Mursu 2002). The other two were the only ones with healthcare organizations as customers. Customer organizations of the software companies were also interviewed. The MINPHIS project was analyzed as the sixth case. (Soriyan 2004)

Most companies were visited three times from November 1999 to spring 2001 first to collect basic information, then to get feedback to the researchers' interpretation and finally to clarify details. Two researchers attended each interview. The interviews were conducted in English and tape recorded. The average time for an interview was 3 hours.

To analyze the cases, the structural model of an activity used in developmental work research was further developed into a version named Activity Analysis and Development (ActAD). A framework of elements and their relations was used as a checklist during interviews and as a lens in analyzing the case projects (Korpela et al. 2004).

During the first interviews, an imaginary ISD project, illustrated in Figure 4 was described to the interviewees to explain what we were interested in. It was based on the theoretical view of ISD as a border-crossing activity which was developed earlier (Korpela et al. 2001). All the interviewees grasped our intentions well.

The results from the first interviews were mapped to the model of activities and activity networks, which was modified to accommodate the increased understanding. In the second interviews, we used wall graphs to guide discussions. 


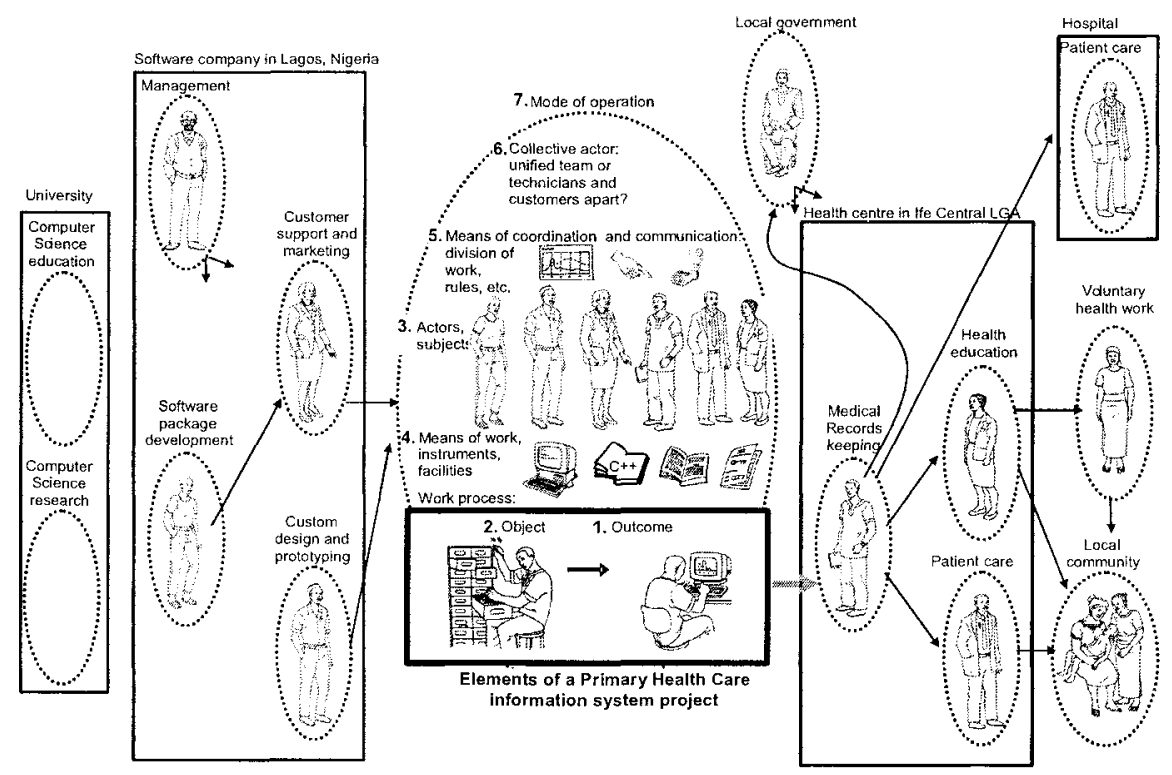

Figure 4. An Illustrated Imaginary ISD Project Used in the Interviews

\subsection{Landscape View through Surveys}

Since there was no prior research on ISD or software companies in Nigeria, we had to combine the insight from the cases with a shallower but wider landscape view and gather basic information through surveys (Gable 1994). Three surveys were conducted (lower left-hand side of Figure 3).

The most fundamental survey aimed at producing an industry profile of the companies with software-related activities. A fully structured and mostly guided questionnaire contained 45 questions in six parts. Ranges were used instead of exact figures to make it fast and easy to respond. It would not have been feasible to conduct the survey by mail in Nigeria, so students were trained to gather the responses by interviews. The Computer Association of Nigeria and the chartered association Computer Professionals of Nigeria provided an initial list of companies, which was updated from advertisements, roadside notices, and all possible sources. The researchers conducted the first interviews, after which the students traveled to all 37 states of Nigeria to contact as many companies as possible. (Soriyan 2004)

Another questionnaire-based survey focusing on systems analysis and design education was conducted using semi-structured interviews in all Nigerian universities offering Computer Science. This survey was conducted by the Nigerian researcher in person. (Soriyan 2004)

The third survey focused on the risk factors of software projects, as identified by project managers. The idea was to repeat an earlier study conducted in the United 
States, Hong Kong, and Finland as precisely as possible to get comparative information. The Delphi method was used in three phases, with a two-round third phase. A subset of 11 software companies in Lagos was initially selected, representing big and small companies, indigenous and foreign-owned. Interviews were conducted mainly by Nigerian research assistants from late 1998 to May 2000. The number of respondents decreased from 39 to 6 , and it was concluded that consensus was not achieved in Nigeria. (Mursu et al. 2003)

\section{EMPIRICAL RESULTS: THE PROFILE OF SYSTEMS DEVELOPMENT IN NIGERIA}

In the following subsections, we briefly summarize the responses to five of the six research questions. The empirical research did not provide sufficient data on the current situation regarding RQ5 about the impact on clients and sustainability.

\subsection{Software Industry in Nigeria (RQ1, RQ2)}

Altogether, 103 software companies were included in the survey, meaning companies that develop their own software or provide information systems services. We estimate that the total number of software companies in Nigeria might be between 150 and 200 (i.e., about one company per one million people). This does not include hardware vendors, training companies, etc. The software companies are located mostly (80 percent) in the southern part of Nigeria, with 49 percent in metropolitan Lagos State alone. They are mostly (96 percent) Nigerian owned. (Soriyan 2004)

A typical (46 percent) software company's staff strength is in the range of 11 to 50 people, while 34 percent had between 1 and 10 employees. Very few companies had more than 250 employees. An average ( 44 percent) software company had between 1 and 5 IT professionals, while 27 percent had between 6 and 15 , and only 6 percent more than 50 IT professionals. The IT workforce was relatively young, mostly within the age brackets 20-29 and 30-39 years. Mostly they had at least a Bachelors degree. The average work experience was in the range of 1 to 5 years. (Soriyan 2004)

The customers' main business focus was studied using the international trade classification. The biggest customer sector was "private sector services," where 59 percent of the software companies had customers. Thirty percent of the companies had 1 to 10 customers, 49 percent had 11 to 50 customers. Almost all companies (87 percent) used fourth generation programming tools ( 43 percent along with a lower level programming language).

Most ( 75 percent) companies offered an imported package among their services ( 25 percent as the only option, among them 15 percent without local adjustments), but a majority ( 75 percent) also offered self-made software ( 25 percent as the only option), with 55 percent offered tailoring from scratch ( 5 percent as the only option). (Soriyan 2004)

In summary, the software industry in Nigeria consists mostly of small local companies, few of them planning to export to other countries. Foreign software packages 


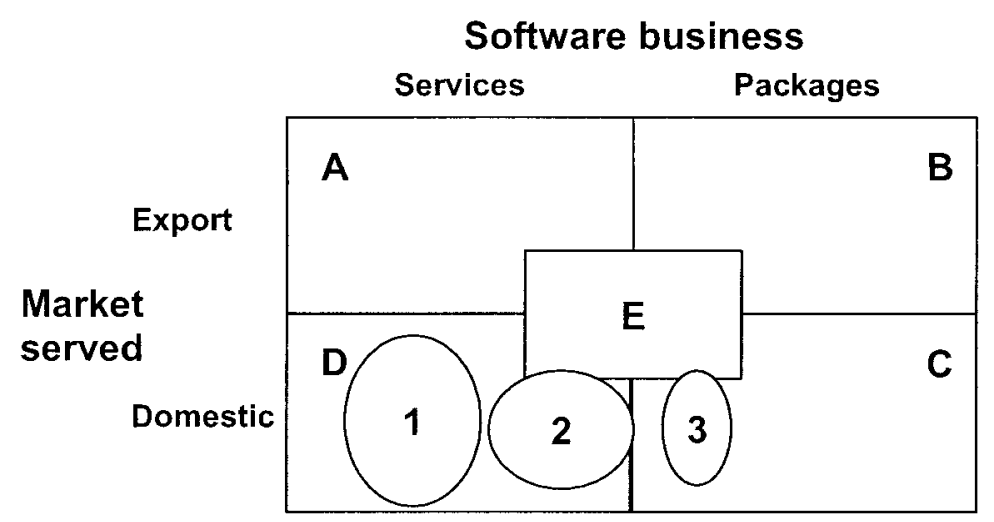

Figure 5. The Current Position of Nigerian Software Industry Within the Heeks Model

predominate, and the software industry provides services including adjustment of these packages to local requirements, installation, configuration, and maintenance. The industry also provides local package development and tailor-made software. Customization is more common than software packaging.

Richard Heeks (1999) presented a model for the strategic positions occupied by the software industry in various countries (see Figure 5). Companies in quadrant A export software services (e.g., programming) to foreign countries, those in B export software packages, those in $\mathrm{D}$ provide services to domestic markets, those in $\mathrm{C}$ produce packages for domestic consumption, and those in $\mathrm{E}$ take a little of each. The ovals in Figure 5 present clusters of Nigerian software industry. Companies in cluster 1 provide services based on an imported package, those in 2 provide services like consultancy and tailoring without a package base, and those in 3 develop and customize packages by themselves for local use. The sizes of the ovals give an idea of the sizes of the respective markets.

\subsection{Systems Development Practice in Nigeria (RQ4)}

ISD projects are usually quite small (average team size was within the range of 1 to 5 IT staff in 68 percent of companies) and short (48 percent last for up to 6 months, 31 percent about a year). For analysis and design, most ( 65 percent) companies had an in-house developed formal methodology in use ( 48 percent as the only option), 36 percent had a text-book methodology in use, while 31 percent had an informal methodology in use and 2 percent had no methodology. (Soriyan 2004)

In the five case studies, the research focused on the relation between the software company and a customer (Figure 6) and on the inner structure of the ISD activity. All cases were professionally ambitious and advanced. Contextual problems were also the same for all of the companies, maybe less for the foreign-owned big companies. The main differences were in the size, user relationships, organization, and formality of activities. The cases and the surveys supported each other quite well. (Mursu 2002; Soriyan 2004) 


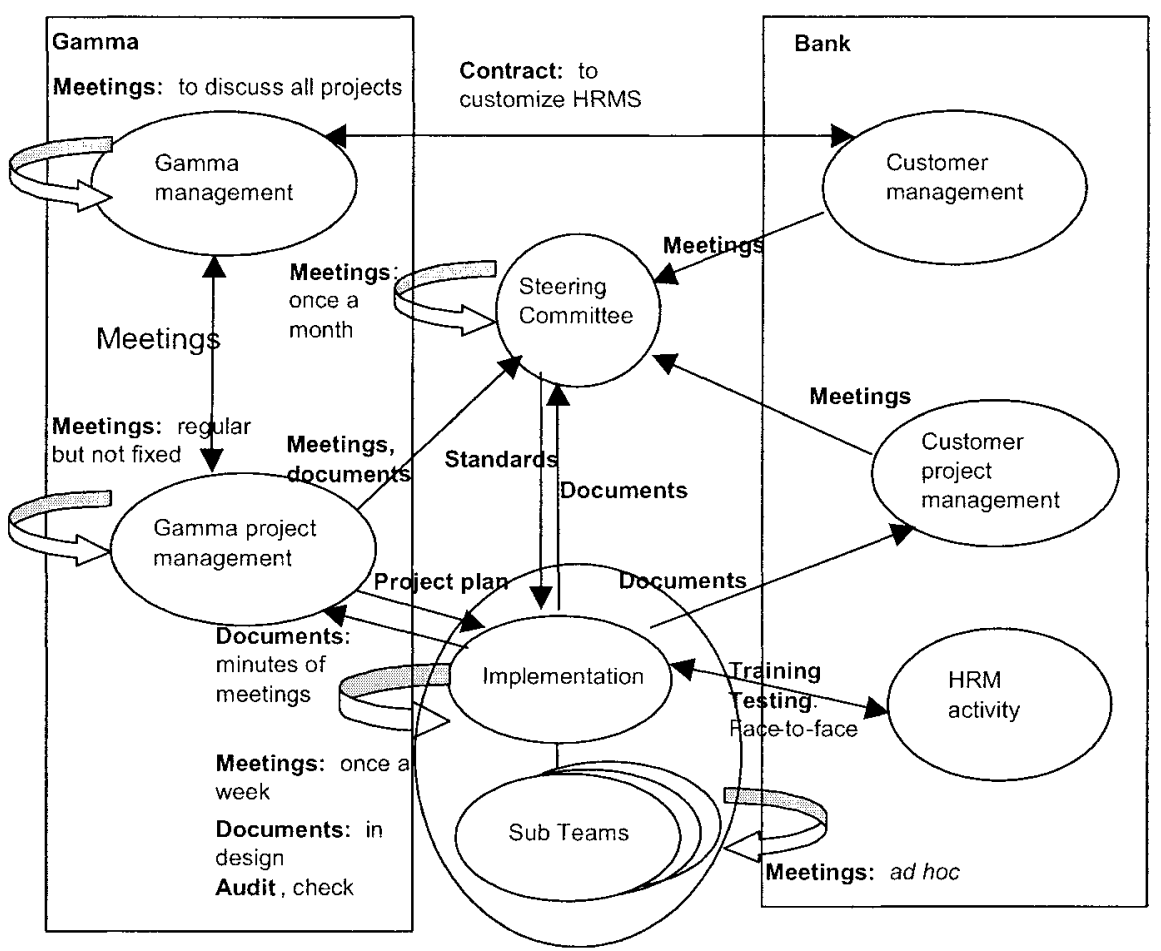

Figure 6. A Sample Analysis of Activity Networks and Means of Networking Around ISD in Software Company Gamma and its Customer (a Bank)

The history of the MINPHIS project since 1989 was analyzed in the same manner. It was realized that the project had gone through four phases from in-house development to a national scope with several customers, each phase characterized by a different network of activities. Despite an experiment in community involvement (Korpela et al. 1998), system development focused first on administrative and then on clinical benefits within the hospital. The development personnel changed several times and remained very few, resulting in mainly ad hoc methodologies. (Soriyan 2004)

\subsection{Systems Development Education in Nigeria (RQ3, RQ6)}

There were 47 universities in Nigeria at the time of the survey ( 24 federal, 18 statelevel. and 4 private). Only 26 offered courses in Computer Science. None of them had the number of academic staff required by the Nigeria Universities Council (NUC) stipulations. None of the universities had up to 50 percent of the required hardware and software tools and almost none had a software engineering laboratory mandated by the 
NUC minimum requirement; in fact some universities did not have any computers for their software development courses.

Software development education in Nigeria was within the Computer Science departments. The NUC defined the minimum curriculum standard, which was mandatory for the universities. There were a few variations introduced by the individual universities. The minimum standard provided by the NUC was intended to be reviewed after 10 years, although in practice individual universities review their curriculum every 2 years. Only the waterfall model was taught in the universities. Software management excluding risk management was also taught within software engineering (SE). (Soriyan 2004)

System analysis and design (SAD) as taught in the universities was closely related to SE. It covered the software development life cycle from software requirements to design. ISD was not mentioned in all the responses, although SE, SAD, and some topics in database design and management dealt with some issues in ISD. (Soriyan 2004)

\section{IMPLICATIONS TO PRACTICE: GUIDELINES AND RECOMMENDATIONS}

In the following subsections, we draw practical implications regarding the research questions.

\subsection{Recommendations to Software Companies (RQ1, RQ2)}

Originally we had no intention to obtain business policy implications from software companies, only to gather basic information about them. However, analyzing the data produced the following recommendations as an extra outcome.

Good knowledge of market needs and good personal connections are the strengths of Nigerian software companies over foreign competition. It is, therefore, reasonable for them to focus on local markets. In Figure 7, the lower half of the Heeks model (i.e., the local market-oriented positions) is further elaborated (Soriyan 2004; Soriyan and Heeks 2004). It is divided into two rows, for private and public sector markets. The service quadrant $\mathrm{D}$ is divided into three columns, D1 denoting services based on foreign packages, D2 services that are not based on packages, and D3 tailoring applications from scratch. The package quadrant $\mathrm{C}$ is divided into two columns, $\mathrm{C} 1$ being parallel versions for each customer and $\mathrm{C} 2$ actual configurable packages.

In our analysis, columns D1 and D2 are unstable since they are not based on local software development experience. In columns D3, C1, and C2 the companies have more control over their destinies since their services are based on their own products. It is reasonable that companies gain experience and customers in columns D1, D2, and D3, but we recommend that they take steps toward column $\mathrm{C} 2$. That movement mainly takes place in the private sector (i.e., row A), where there is more market demand.

This recommendation is problematic from the perspective of the healthcare sector which resides mainly on row $B$. In the software industry survey, only two companies were in position $\mathrm{D} 3_{\mathrm{B}}$ in the healthcare sector, and the MINPHIS project is in $\mathrm{C} 2_{\mathrm{B}}$. 


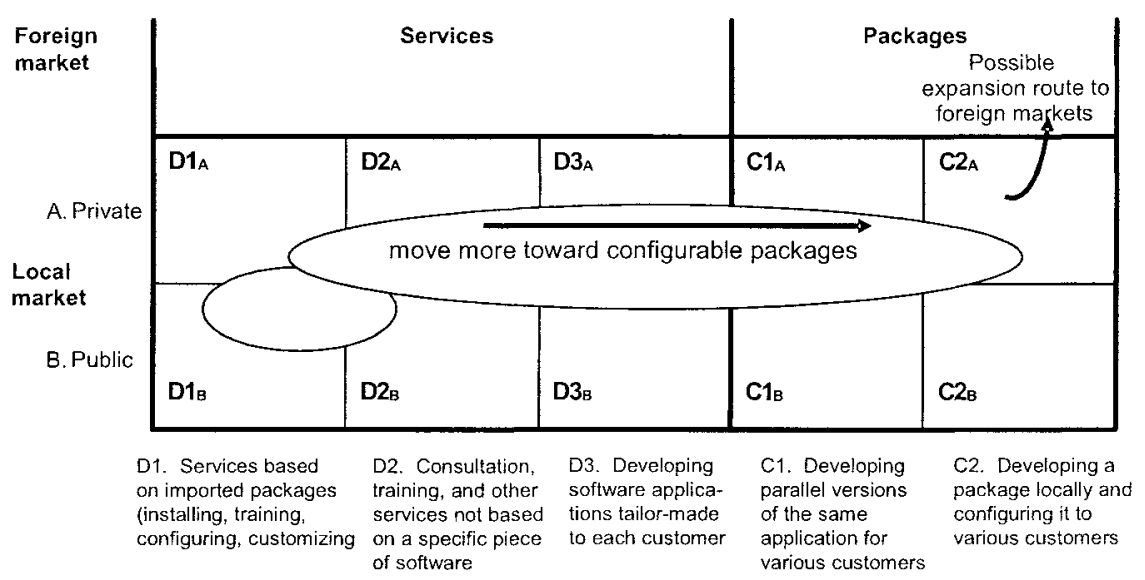

Figure 7. The Proposed Strategic Position for the Nigerian Software Industry

\subsection{Recommendations on ISD: Participation, Risk, and Sustainability (RQ4, RQ5)}

The industry survey, case studies, and action experience confirmed that user participation in ISD is important and possible even in the severely constrained conditions of a developing country, contrary to some earlier doubts (Avgerou and Land 1996). It is, however, also important to note that there is very little that would apply universally, and the specific promoters and inhibitors of participation vary even from organization to organization (Puri et al. 2004). Thus methods developed within participatory development (Kensing and Blomberg 1998) should be adapted to local needs in specific contexts.

The Delphi study resulted in a list of the most common risk factors in software projects in Nigeria. The most notable differences compared to the risk factors in the United States, Hong Kong, and Finland dealt with the socio-economic context of the country, infrastructure, and relationships with inexperienced users. Only a few items on the list deal with the technical aspects of software development (Mursu et al. 2003). The checklist of risk factors can guide less experienced Nigerian software project managers to address them early enough. However, the international risk study was limited to software projects only, and did not cover the introduction or use of ICT in organizations.

The case studies corroborated our initial assumption that the sustainability of information systems in organizations is an important issue. We then developed a model for sustainability analysis by combining literature on sustainable and appropriate technology (Oyomno 1996; Pellegrini 1980) with the activity network model (Mursu et al. 2005). The model would help project managers to design and implement information systems that are sustainable. The model needs to be developed into an easily applicable form before it can be tried in practice. 


\subsection{Implications to University Education (RQ3, RQ6)}

The absence of ISD in the university curriculum may explain some of the deficiencies in system development practice noted in the industry survey. Furthermore, the curriculum focuses on the technical construction of software systems, but the problems confronting the software industry as revealed by the survey were mostly not included in the curriculum. The education should have more focus on the activities at the early and late development phases which deal with customer relations, understanding their requirements and how best to support them during and after implementation. Project management and social skills in general should be emphasized. (Soriyan 2004)

Software practitioners also had complaints about the software engineering education being behind today's reality. Universities should address this persistent problem by getting more closely engaged with the industry. The departments are so severely underresourced that satisfactory results are simply impossible without increased government funding. International research relations should be used to partly relieve the problems of outdated contents and dearth of resources.

\section{DISCUSSION: IMPLICATIONS TO RESEARCH}

In the following subsections, we discuss the methodological and theoretical implications.

\subsection{Studying Information Systems in Context}

Our experience strongly supports the use of a combination of methods for getting a landscape view and insight in parallel in a situation where even basic topics have not been studied before. This situation is not uncommon in many developing countries. Routinely used methods and research designs from industrialized countries can be unfeasible in developing countries; for example, posted questionnaires could not work in our research, and the scope of the international software project risk study was too narrow to capture essential aspects of the software business in Nigeria (Mursu et al. 2003).

The study in Nigeria operated on three levels. The activity level and research methodology on that level received most of the attention. The ActAD framework and the generic model of ISD as an activity were operationalized into usable checklists without losing touch with the complexity of human activity as a real-life phenomenon. The aspects of ActAD that could not be sufficiently put to practice were historical analysis and proceeding into a phase of work development in software companies.

Unlike the activity level, the organizational level of analysis was not supported by a theoretical framework. In hindsight, empirical research on this level suffered from lack of methodological guidance, and produced a rather superficial understanding based on ad hoc frameworks. Neo-institutional theory (Nielsen and Koch 2004) might be a good candidate of an organizational-level social theory that could inform design and share activity theory's emphasis on history and contradictions. To maintain the integra- 
tive nature of the levels of analysis (Tobach 1999), activities need to be included as elements in the institutional framework, without reducing institutional phenomena to activities.

The societal level of analysis was not bound to a specific theoretical framework, either. Structuration theory (Giddens 1984; Walsham 1993) has been the most commonly used framework on that level in IS recently, but it is so generic that it is not easy to study the relations between micro and macro level phenomena with it (Macome 2003).

\subsection{Nigeria Versus Africa Versus Developing Countries}

Starting from 2004, INDEHELA has continued with a new phase, INDEHELAContext, and research groups from Mozambique and South Africa have joined. Lessons from the first phase have been used in elaborating on the research design. Contextual and impact issues, which were understudied in the first phase, are now in focus.

The same basic chain of activities around ISD is still studied in each country, but the domain of application is now explicitly healthcare (Figure 8; compare with Figure 2). Local companies are no longer the only form of software organizations studied, while in Mozambique nongovernmental organizations (NGOs) have a major role in healthcare information systems (Braa et al. 2004). Small, private medical practices provide an important part of primary healthcare services in South Africa, for instance, so both the public and private sector must be studied (de la Harpe et al. 2005).

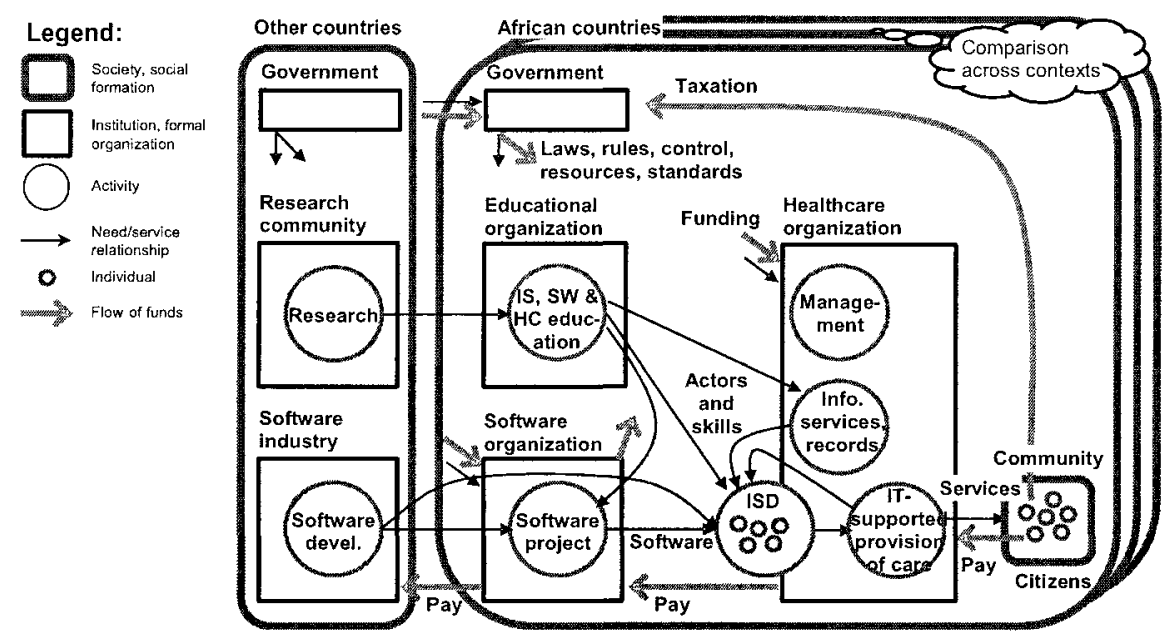

Figure 8. The Expanded Research Framework of 2004-2007 
Local software activities by NGOs can collaborate with open source developers within a global network, while commercial companies often have other types of foreign liaisons. Educational activities in universities have international research liaisons, too. It is thus justifiable to include international linkages into the set of research objects, as indicated in a generic form in Figure 8.

Another factor that was missing in INDEHELA-Methods is the government. Particularly in healthcare, the government has the power to provide much control and guidance on whether and what kind of information systems are introduced in organizations. Healthcare and education are also mostly funded by the government, and financial relations (examples of them depicted by wide arrows in Figure 8) are indeed among the most important additions to the research framework. Financial viability is one of the elements of long-term sustainability, and affordability is a critical issue when money is scarce.

It has also become necessary to zoom in from activities to individuals (small circles in Figure 8). At least when studying the impact of IS in healthcare on the services provided to citizens, it is necessary to study if the impact is equal or not on different groups of individuals. Similarly, different professional, ethnic, or gender groups can have different roles in and experience the consequences of ISD differently (de la Harpe et al. 2005). Geographic and other communities (depicted by a small rounded box in Figure 8), including communities of practice (Wenger 1998), need to be studied as social formations different from activities and formal organizations.

Having three different Sub-Saharan African countries in the research network, we are now able to accumulate empirical research results from different organizational, societal, cultural, and political contexts. This will enable us to draw at least hypotheses on how contextual differences affect phenomena of ISD at the activity level. However, this implies that the specific contexts need to be recorded in each empirical study, and therefore there needs to be some common agreement on what "the context" might comprise (Mursu et al. 2005). This is still work in progress. To enable comparison between contexts, the generic framework of Figure 8 must be transformed into a specific framework in each country. For instance, the generic "healthcare organization" in Figure 8 needs to be expanded into an analysis of the specific "healthcare landscape" in each specific country - institutions, services, activities, and flows of funding (de la Harpe et al. 2005).

\section{CONCLUSIONS: ISD AND HUMAN DEVELOPMENT REVISITED}

We summarized the results of over 15 years of European-African research collaboration, mainly on and around ISD in Nigeria. The contributions fall into four categories (right-hand side of Figure 3). First, the research contributed previously nonexistent empirical knowledge about software companies and their ISD practice in a severely constrained context. Second, the research methodological contribution was to combine methods for landscape view and insight. Third, the practical contribution consisted of tentative recommendations for software companies regarding strategic orientation (unintended contribution) and methods for risk and sustainability analysis, as well as 
recommendations for universities regarding the relevance of the education they provide. Fourth, theoretical contributions to Information Systems were frameworks for analyzing activities, particularly ISD, in institutional and societal contexts. The recommendations and frameworks are further tested and developed in the new phase.

In the beginning we asked: Can ISD in Nigeria by Nigerians contribute to human development, specifically to people's health, in Nigeria? The following subquestions spiral toward the ultimate answer:

- Can ICTs contribute to socio-economic development in Nigeria/Africa? Yes, there has been no doubt about this among researchers for the past decade, although the relation is not automatic. Some uses of ICTs can be a waste, some beneficial, as anywhere.

- Can ISD in NigerialAfrica be practiced in such a way that it contributes to human development as defined by Sen, particularly people's health? This is a more challenging question. An organizational information system in a private clinic can contribute to the financial viability of the enterprise without improving health services. Experiments in community involvement in MINPHIS and South Africa indicate that it is actually quite difficult to introduce organizational information systems in healthcare in such a way that the impact on people's health is directly addressed. However, the experiments show that it is not impossible.

- Are ISD practitioners in Nigeria capable of practicing ISD in such a way? According to our surveys and case studies, software professionals in local companies in Nigeria are technically quite capable, understand the importance of user involvement, and have good knowledge of the local needs.

- Do ISD practitioners in Nigeria currently contribute to people's health? Only two software companies out of 103 had anything to do with healthcare, and even those two focus on administrative and financial benefits. So, in practice, Nigerian ISD practitioners do not significantly contribute to people's health.

- Why is this so? According to our surveys, there is a dearth of human resources, particularly nontechnical skills of project management, and practicable methods for sustainability and impact analysis, communication, and participation, which are required to ensure that ICT does not become a white elephant. Even more importantly, as our analysis of the strategic position of Nigerian software companies points out, it is not profitable to contribute to people's health or to the "real freedoms that people enjoy" in general.

- What should be done? ISD education should be strengthened and expanded, as we recommended earlier. However, the results of INDEHELA-Methods do not tell if and how the need for financial profitability of software organizations can be combined with the unprofitable need to develop information systems that contribute to health. More research in the second phase is needed to address this ultimate question. 
These questions referred specifically to Nigeria or Africa. However, in any country any information systems practitioner can ask the same question: Does information systems practice in my country and by me contribute to the real freedoms that people enjoy, in my country and in my world?

\section{Acknowledgments}

This paper is based on research funded by the Academy of Finland grants no. 39187 (INDEHELA-Methods,1998-2001), 201397, and 104776 (INDEHELA-Context, 2003, 2004-2007).

\section{References}

Avgerou, C., and Land, F. "Examining the Appropriateness of Information Technology," in S. C. Bhatnagar and M. Odedra (eds.), Social Implications of Computers in Developing Countries, New Delhi: Tata McGraw-Hill, 1992, pp. 26-41.

Avison, D. E. "The 'Discipline' of Information Systems: Teaching, Research and Practice," in J. Mingers and F. Stowell (eds.), Information Systems: An Emerging Discipline, Berkeley, CA: McGraw-Hill, 1997, pp. 113-136.

Berg, M., Aarts, J., and van der Lei, J. "ICT in Health Care: Sociotechnical Approaches," Methods of Information in Medicine (42:4), 2003, pp. 297-330.

Braa, J., Monteiro, E., and Sahay, S. "Networks of Actions: Sustainable Health Information Systems Across Developing Countries," MIS Quarterly (28:3), 2004, pp. 337-362.

Checkland, P. "From Framework through Experience to Learning: The Essential Nature of Action Research," H. E. Nissen, H. K. Klein, and R. Hirschheim (eds.), in Information Systems Research: Contemporary Approaches and Emergent Traditions, Amsterdam: Elsevier, 1991, pp. 397-403.

Daini, O. A., Korpela, M., Ojo, J. O., and Soriyan, H. A. "The Computer in a Nigerian Teaching Hospital: First-Year Experiences," in K. C. Lun, P. Degoulet, T. E. Piemme, and O. Rienhoff (eds.), MEDINFO'92: Proceedings of the Seventh World Congress on Medical Informatics, Amsterdam: Elsevier, 1992, pp. 230-235.

de la Harpe, R., Korpela, M., and Kamanga, E. "The Potential of Community Informatics in Small Private Medical Practice in South Africa," in G. Erwin, W. Taylor, A. Bytheway, and C. Strumpher (eds.), Proceedings of the $2^{\text {nd }}$ Annual Conference of the Community Informatics Research Network, Cape Town, South Africa, August 23-26, 2005, pp. 101-117.

Engeström Y. Learning by Expanding: An Activity-Theoretical Approach to Developmental Research, Helsinki: Orienta-Konsultit, 1987.

Gable, G. "Integrating Case Study and Survey Research Methods: An Example in Information Systems," European Journal of Information Systems (3:2), 1994, pp. 112-126.

Giddens, A. The Constitution of Society: Outline of the Theory of Structuration, Cambridge, UK: Polity Press, 1984.

Heeks, R. "Software Strategies in Developing Countries," Communications of the ACM (42:6), 1999, pp. 15-20.

INDEHELA. Project web site and archive from 1995 (available online at http://www.uku.fi/ tike/his/indehela).

Kensing, F., and Blomberg, J. "Participatory Design: Issues and Concerns," Computer Supported Cooperative Work (7), 1998, pp. 167-185.

Korpela, M. Nigerian Practice in Computer Systems Development, Reports TKO-A31, Helsinki University of Technology, Espoo, Finland, 1994. 
Korpela, M., Mursu, A., and Soriyan, H. A. "Information Systems Development as an Activity," Computer Supported Cooperative Work (11), 2002, pp. 111-128.

Korpela, M., Mursu, A., and Soriyan, H. A. "Two Times Four Integrative Levels of Analysis: A Framework," in N. L. Russo, B. Fitzgerald, and J. I. DeGross (eds.), Realigning Research and Practice in Information Systems Development: The Social and Organizational Perspective, Boston: Kluwer Academic Publishers, 2001, pp. 367-377.

Korpela, M., Mursu, A., Soriyan, A., Eerola, A., Häkkinen, H., and Toivanen, M. "IS Research and Development by Activity Analysis and Development: Dead Horse or the Next Wave?," in B. Kaplan, D. P. Truex, D. Wastell, A. T. Wood-Harper, and J. I. DeGross (eds.), Information Systems Research: Relevant Theory and Informed Practice, IFIP TC8/WG8.2 20th Year Retrospective, Boston: Kluwer Academic Publishers, 2004, pp. 453-470.

Korpela, M., Soriyan, H. A., Olufokunbi, K. C., and Mursu, A. "Made-in-Nigeria Systems Development Methodologies: An Action Research Project in the Health Sector," in C. Avgerou and G. Walsham (eds.), Information Technology in Context: Studies from the Perspective of Developing Countries, Aldershot, UK: Ashgate, 2000, pp. 134-152.

Korpela, M., Soriyan, H. A., Olufokunbi, K. C., Onayade, A. A., Davies-Adetugbo, A., and Adesanmi, D. "Community Participation in Health Informatics in Africa: An Experiment in Tripartite Partnership in Ile-Ife, Nigeria," Computer Supported Cooperative Work (7:3-4), 1998, pp. 339-358.

Macome, E. The Dynamics of the Adoption and Use of ICT-Based Initiatives for Development: Results of a Field Study in Mozambique, unpublished doctoral dissertation, University of Pretoria, South Africa, 2003 (available online at http://petd.up.ac.za/thesis/available/etd02192003-161649/).

Mandil, S. H., Moidu, K., Korpela, M., Byass, P., and Forster, D. (eds.). Health Informatics in Africa-HELINA 93: Proceedings of the First International Conference, Amsterdam: Elsevier, 1993.

Mbarika, V. W. A., Okoli, C., Byrd, T. A., and Datta, P. "The Neglected Continent of IS Research: A Research Agenda for Sub-Saharan Africa," Journal of the Association for Information Systems (6:5), 2005, pp. 130-170.

Mursu, A. Information Systems Development in Developing Countries. Risk Management and Sustainability Analysis in Nigerian Software Companies, Jyväskylä Studies in Computing 21, University of Jyväskylä, Jyväskylä, Finland, 2002.

Mursu, A., Lyytinen, K., Soriyan, H. A., and Korpela, M. "Identifying Software Project Risks in Nigeria: An International Comparative Study," European Journal of Information Systems (12), 2003, pp. 182-194.

Mursu, A., Tiihonen, T., and Korpela, M. "Contextual Issues Impacting the Appropriateness of ICT: Setting the Stage for Socio-Technical Research in Africa," in A. O. Bada and A. Okunoye (eds.), Proceedings of the Eighth International Working Conference of IFIP WG 9.4. Enhancing Human Resource Development through ICT, Nigeria, May 26-28, 2005, pp. 348-358.

Musa, P. F., Meso, P., and Mbarika, V. W. "Toward Sustainable Adoption of Technologies for Human Development in Sub-Saharan Africa: Precursors, Diagnostics, and Prescriptions," Communications of the Association for Information Systems (15), 2005, pp. 592-608.

Myers, M. D. "Qualitative Research in Information Systems," MIS Quarterly (21:2), 1997, pp. 241-242 (MISQ Discovery archival version, June 1997, available online at http://www.misq.org/discovery/MISQD isworld/; last modified: July 26, 2005, www.qual.auckland.ac.nz).

Nielsen, K., and Koch C. A. (eds.). Institutionalism in Economics and Sociology: Variety, Dialogue and Future Challenges, Cheltenham, UK: Edward Elgar, 2004.

Nwachuku, M. A. Computers for Industrial Management in Africa: The Case of Nigeria, United Nations Industrial Development Organization, V.89-57624, PPD.126, United Nations, 1989. 
Orlikowski, W. J., and Baroudi, J. J. "Studying Information Technology in Organizations: Research Approaches and Assumptions," Information System Research (2:1), 1991, pp. 128.

Oyomno, G. "Sustainability of Governmental Use of Microcomputer-Based Information Technology in Kenya," in M. Odedra-Straub (ed.), Global Information Technology and Socio-Economic Development, Nashua, NH: Ivy League Publishing, 1996, pp. 19-34.

Pellegrini, U. "The Problem of Appropriate Technology," in A. De Giorgio and C. Roveda (eds.), Criteria for Selecting Appropriate Technologies under Different Cultural, Technical and Social Conditions: Proceedings of the IFAC Symposium, Oxford, UK: Pergamon Press, 1980, pp. $1-5$.

Puri, S. K., Byrne, E., Nhampossa, J. L., and Quraishi, Z. B. "Contextuality of Participation in IS design: A Developing Country Perspective," in Artful Integration: Interweaving Media, Materials and Practices-PDC 2004, Proceedings of the Participatory Design Conference, Toronto, Canada, July 27-31, 2004, pp. 42-52.

Sen, A. Development as Freedom, Westminster, MD: Alfred A. Knopf, 1999.

Soriyan, H. A. A Conceptual Framework for Information System Development Methodology for Educational and Industrial Sectors in Nigeria, unpublished doctoral dissertation, Obafemi Awolowo University, Ile-Ife, Nigeria, 2004.

Soriyan, H. A., and Heeks, R. "A Profile of Nigeria's Software Industry," Working Paper No.21/2004, Institute for Development Policy and Management, University of Manchester, Manchester, UK, 2004 (available online at http://www.sed.manchester.ac.uk/idpm/ publications/wp/di/di_wp21.pdf).

Tobach, E. "Activity Theory and the Concept of Integrative Levels," in Y. Engeström, R. Miettinen, and R. Punamäki (eds.), Perspectives on Activity Theory, Cambridge, UK: Cambridge University Press, 1999, pp. 133-146.

UNDP. Human Development Report 2001: Making New Technologies Work for Human Development, United Nations Development Program, New York: Oxford University Press, 2001 (available online at http://hdr.undp.org/reports/global/2001/en/).

UNDP. Human Development Report 2004: Cultural Liberty in Today's Diverse World, United Nations Development Program, New York: Oxford University Press, 2004 (available online at http://hdr.undp.org/reports/global/2004/).

Walsham, G. "Globalization and IT: Agenda for Research," in R. Baskerville, J. Stage and J. I. DeGross (eds.), Organizational and Social Perspectives on Information Technology, Boston: Kluwer Academic Publishers, 2000, pp. 196-210.

Walsham, G. Interpreting Information Systems in Organizations, Cambridge, UK: John Wiley \& Sons, 1993.

Wenger, E. Communities of Practice: Learning, Meaning, and Identity, New York: Cambridge University Press, 1998.

Yin, R. Case Study Research: Design and Methods ( $2^{\text {nd }}$ ed.), Beverly Hills, CA: Sage Publishing, 1994.

\section{About the Authors}

Mikko Korpela is Research Director of the Healthcare Information Systems R\&D Unit, University of Kuopio, Finland, and an adjunct professor at the Department of Computer Science at the same university. He received his D.Tech. degree in Information Systems at the Helsinki University of Technology in 1994. He is a member of IFIP WG 8.2 and founding secretary of IFIP WG 9.4, a member of IMIA WG HIS and IMIA WG Health Informatics for Development, the founding organizing chair of HELINA, and Health Commission Co-Chair of IFIP World IT Forum 2007. Mikko can be reached at mikko.korpela@uku.fi. For more information on his work, visit his homepage at www.uku.fi/ korpela. 
Anja Mursu is a research director in the Department of Computer Science at the University of Kuopio, Finland. She received her Ph.D. in Information Systems in 2002 at the University of Jyväskylä, Finland. Her research interests include information systems development, sustainability and usability of information systems, and ICT for development in developing countries. For more information on her work, visit her homepage at http:/www.cs.uku.fi/ -amursu/. Anja can be reached at anja.mursu@uku.fi.

H. Abimbola Soriyan is a senior lecturer in the Computer Science and Engineering Department at Obafemi Awolowo University in Ife-Ife, Nigeria. She is the coordinator of the Hospital Information System Unit at the Obafemi Awolowo University. Abimbola received her M.Sc. in Computer Science in 1997 and her Ph.D. (2004) from Computer Science and Engineering Department of Obafemi Awolowo University. Her research interests are in the areas of computer-based hospital and health care information systems, ICTs and development, and cognitive and social issues in the design and use of computer systems. Currently a visiting scholar at Cornell University, Abimbola is working on the deployment of virtual classroom for higher education and investigating the impact of ICT tools on development focusing on education and gender. She is a member if IFIP 9.4. She can be reached at hasoriyan@yahoo.com, hsoriyan@oauife.edu, or has38@cornell.edu.

Retha de la Harpe is a senior lecturer at the Cape Peninsula University of Technology in Cape Town, South Africa. She is currently busy with her Ph.D., titled "The Organisational Implications of Data Quality in a Developing Country: An Actor-Network Theory Perspective." She is a NRF (National Research Foundation) grant holder and most of the research projects investigate information issues in private healthcare and contribute toward an improved understanding of the healthcare landscape in South Africa. She can be reached at delaharper@, cput.ac.za.

Esselina Macome is professor of Information Systems at the Eduardo Mondlane University, Maputo City, Mozambique. She was born in Maputo, Mozambique, and in 1992 achieved her M.Sc. in Information Systems at the University of London (LSE). She received her Ph.D. in Information Technology from the University of Pretoria, South Africa, in 2003. She is a member of IFIP WG 9.4 and HISP (Health Information System Programme). Her research interests include ICT governance, and organizational and social aspects of ICT/IS. Since June 2005, she is one of the general managers at the Central Bank in Mozambique. She can be reached by e-mail at esselina.macome.uem.mz or taila.uffo@tvcabo.co.mz. 